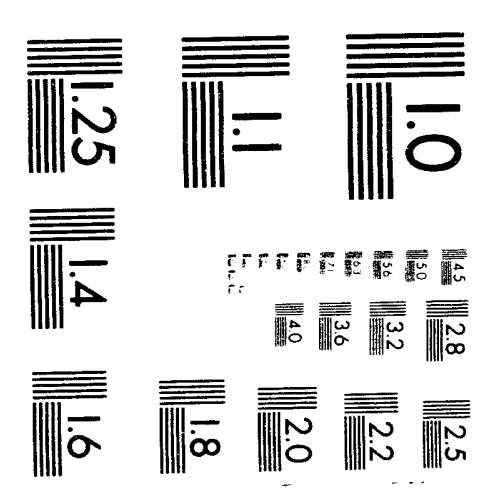



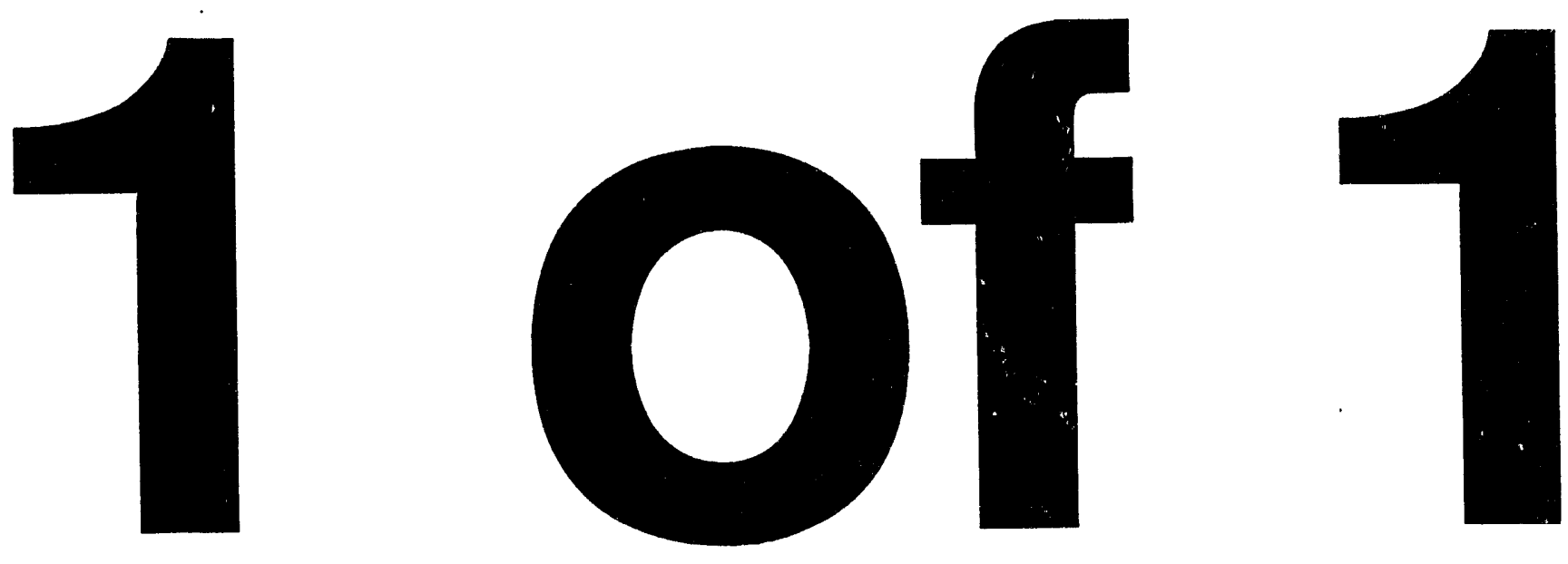
SAND94-8207

Unlimited Release

Printed December 1993

\title{
PROCESS WASTE ASSESSMENT \\ FOR THE \\ DIANA LASER LABORATORY
}

\section{Norman M. Phillips \\ Sandia National Laboratories/California}

\begin{abstract}
This Process Waste Assessment was conducted to evaluate the Diana Laser Laboratory, located in the Combustion Research Facility. It documents the hazardous chemical waste streams generated by the laser process and establishes a baseline for future waste minimization efforts. This Process Waste Assessment will be reevaluated in approximately 18 to 24 months, after enough time has passed to implement recommendations and to compare results with the baseline established in this assessment.
\end{abstract}

\section{MASTER}




\section{CONTENTS}

Page

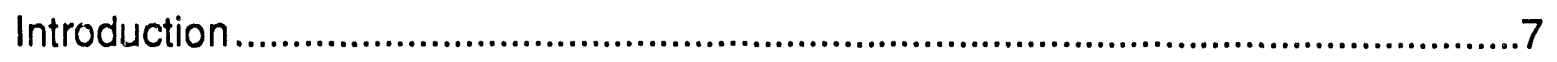

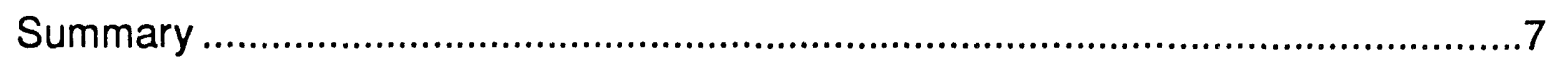

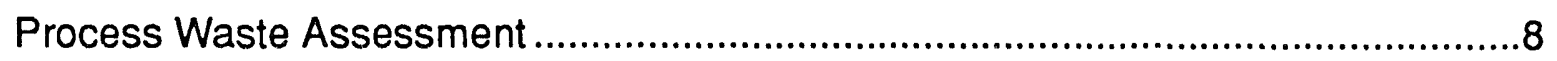

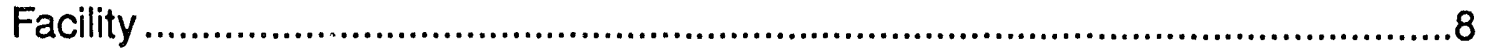

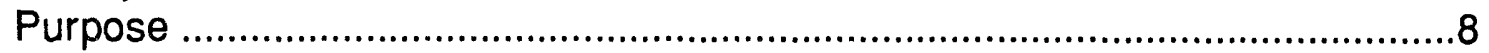

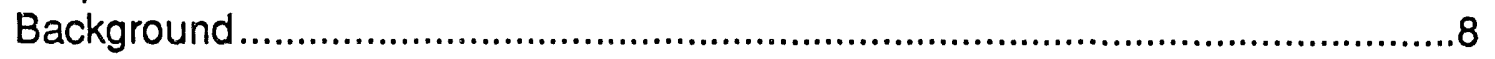

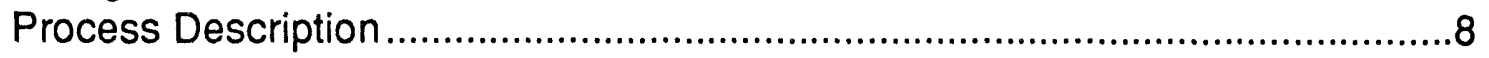

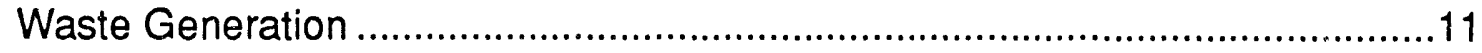

Process Flow and Material Balance.........................................................12

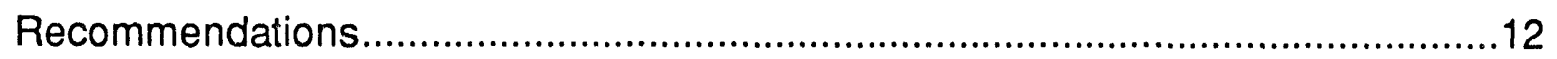

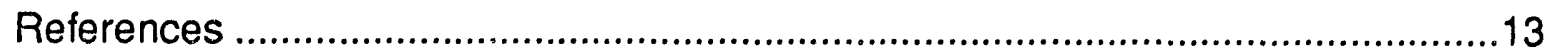

\section{ILLUSTRATIONS AND TABLES}

No.

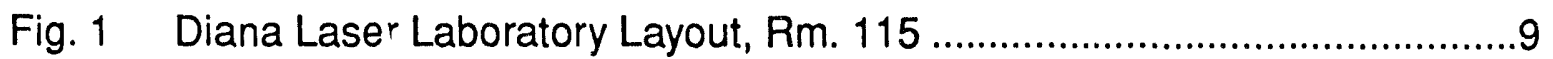

Fig. 2 Diana Laser General Process Flow Diagram .......................................10

Fig. 3 Diana Laser Process Flow and Estimated Material Balance ..................12

Table 1 Diana Laser Hazardous Waste Generation (January 1992 to July 1993). 


\section{PROCESS WASTE ASSESSMENT \\ DIANA LASER LABORATORY}

\section{Introduction}

The Department of Energy (DOE) Orders 5400.1 and 5400.3 mandate the development of a waste minimization program. ${ }^{1,2}$ The program's goals are to:

1. reduce volumes of hazardous wastes and toxicity,

2. implement a system of tracking and reporting improvements, and

3. devise a method for performing assessment and minimization tasks.

To satisfy the requirements of this program, Sandia conducts process waste assessments (PWA) to identify waste generating processes. The information collected from a PWA is then used to identify waste minimization opportunities.

This PWA was conducted on the Diana Laser Laboratory, which is located in the Combustion Research Facility (CRF), according to Sandia's revised Process Waste Assessment Plan. ${ }^{3}$ This PWA documents the hazardous chemical waste streams generated by the process and establishes a baseline for future waste minimization efforts.

The PWA will be reevaluated in approximately 18 to 24 months, after enough time has passed to implement recommendations and to compare results with the baseline established in this assessment.

\section{Summary}

The Diana laser uses a high-current, high-voltage power source to pulse a flashlamp, which excites dye molecules. The dye molecules then release their energy in the form of light. The wavelength of light is determined by the type of dye used. The pulses are emitted to the CRF pulse distribution system. Coumarin 440 dye is used to generate light in the 430-nm region, and Coumarin 521 is used for light pulses in the 531-nm region. 4,5

The dye solution (1:1 alcohol-water solution and dye mixture) is contained in a stainless steel circulation system. It is circulated from a 100-L storage tank (located outside the laboratory) through a set of Pall filters, into the Diana laser, and back to the tank at a rate of about $200 \mathrm{~L} / \mathrm{min} .6$

In 1992, most of the laboratory's hazardous waste was dye solutions (445 gal.), dyecontaminated charcoal (142 lbs.), and used filters ( $51 \mathrm{lbs}$.). Some waste also was generated as a result of charcoal contaminating the alcohol-water mixture after filtering the dye out of the solution. An additional set of Pall filters was installed on the outlet side of the charcoal filter system to solve this problem. ${ }^{4}$ 
The Diana Laser Laboratory initially was selected for a PWA based on its hazardous waste generation in 1992. However, the laboratory's operations were reviewed at the end of 1992 to determine if the Diana laser would still be required for future CRF research programs. Based on the results of the review, in early 1993, CRF management decided to continue operating the laser. However, the laser probably will be operated quite differently than it has been; the operators expect to use only the Coumarin 440 dye, which may last up to two years before needing replacement. Therefore, the volume of hazardous waste will be reduced by an estimated 50 to $60 \% .4$

Overall, the Diana Laser Laboratory personnel are very aware of the need to reduce volumes of hazardous waste and are continuously looking for opportunities to do so.

\section{Process Waste Assessment}

\section{Facility}

The Diana Laser Laboratory, Combustion Research Facility (CRF), Building 906, Room 115.

\section{Purpose}

The main purpose of the Diana laser is to provide laser pulses to the CRF beam distribution system for use in CRF laboratories. ${ }^{6}$

\section{Background}

The Diana Laser Laboratory was initially selected as a candidate for a PWA based on the volume of ethyl alcohol-dye solution, charcoal, and spent filters that it generated as hazardous waste in 1992. However, late in 1992, the laboratory's operation was reviewed to determine if the Diana laser would still be required for the various CRF research programs. In early 1993, CRF management decided to continue using the laser. However, the type of pulses required for future operations will probably be reduced to one, using Coumarin 440 laser dye to generate laser light in the near UV spectrum $(430 \mathrm{~nm})$. If only one dye solution is used, the volume of used alcohol-dye solution and charcoal will be reduced by an estimated 50 to $60 \% .^{4}$

Due to the proposed changes in the laboratory's operation, this PWA will primarily serve as a baseline for evaluating future waste-generating processes in the laboratory.

\section{Process Description}

A layout of the laboratory is shown in Fig. 1. Listed below are the Diana laser system's primary components:

- laser oscillator and amplifiers,

- high-voltage power supplies,

- energy storage capacitors,

- pulse-forming networks for the flashlamps, and

- dye solution pumping system and storage tank. 


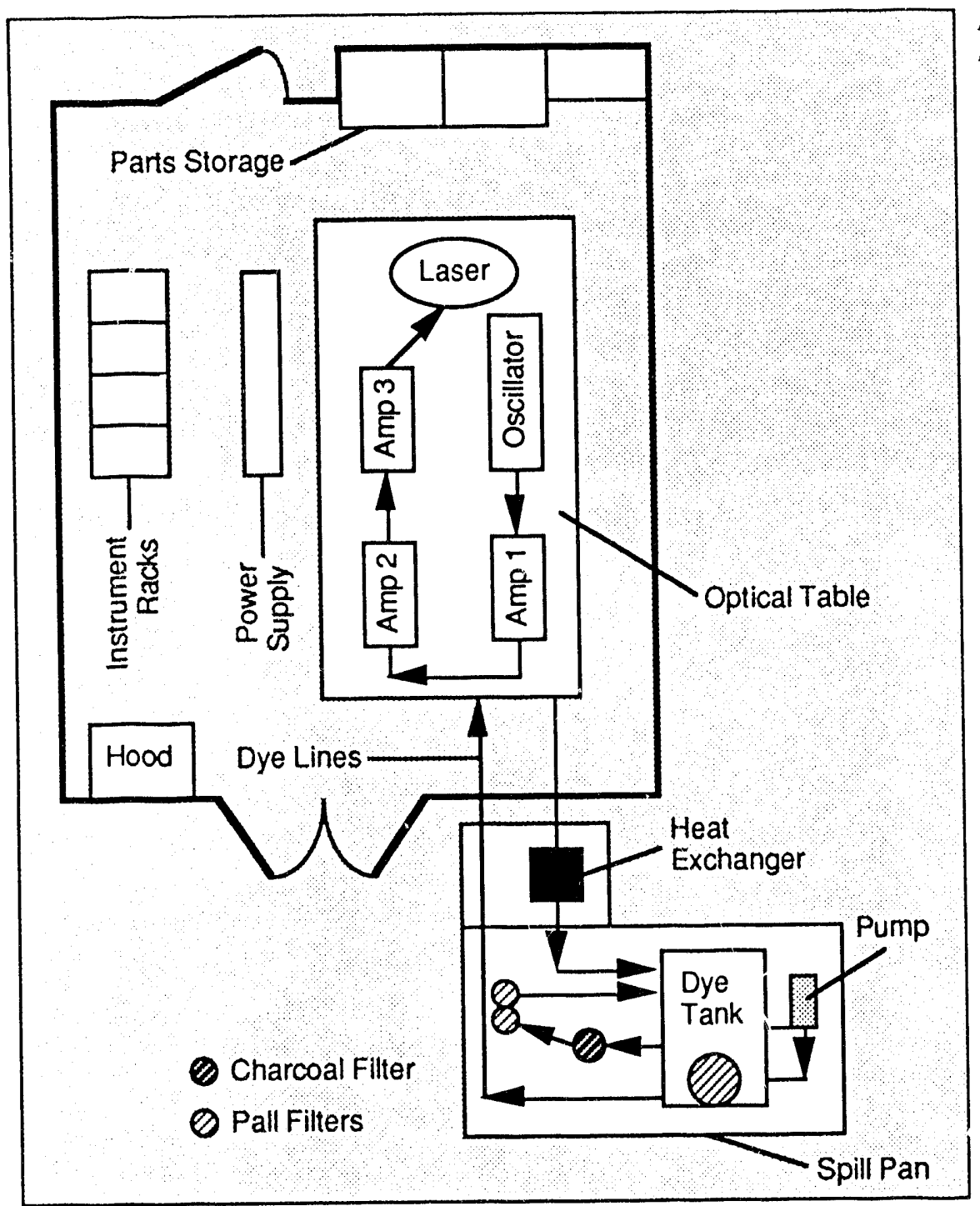

Figure 1. Diana Laser Laboratory Layout, Rm. 115.

Diana is a Class IV dye laser operating through the visible spectrum, at $10-50 \mathrm{~W}$ average and 1-5 MW peak. The laser energy is $1-5 \mathrm{~J}$ at $10 \mathrm{~Hz}$ in $1.5-\mu \mathrm{sec}$ pulses. High-current, high-voltage electrical sources are used to power the flashlamp-pumped dye laser. The energy storage capacitors for the flashlamp discharge circuits can store up to $250 \mathrm{~J}$ each at $25 \mathrm{kV}$. The flashlamp simmer power supplies can generate $900 \mathrm{VDC}$ open circuit and 400 VDC at 2 A. $^{6}$

Several other continuous lasers are used in the Diana Laser Laboratory for alignment and calibration purposes. An air-cooled argon-ion laser (25-MW) is used to bore-sight Diana for alignment. 6

The dye solution is made up of ethyl alcohol mixed 1:1 with water and an organic dye. It is contained in a stainless steel circulation system, comprising plumbing and a metal cabinet, which forms a double enclosure for the dye's 100-L storage tank. The storage tank, pump, and cabinet are located outside the building and are protected by a traffic barrier. The pump and cabinet sit in a stainless steel pan that can hold all the liquid in the system. The 
room is also set up so that it will contain a large spill or leak. A flammable vapor detector, installed under the optical table, shuts down the electrical system and sounds an alarm in case of a leak. The dye pump also shuts down if an interlock is open in the laser control system. 6

The system circulates the solution from the storage tank, through the laser, and back to the storage tank at a rate of approximately $200 \mathrm{~L} / \mathrm{min}$. During circulation, the dye solution flows through a Pall filter. The system can also filter the dye from the alcohol-water solution by passing it through charcoal. The solution is then passed through two other Pall filters to remove any remaining charcoal, which causes problems with pulse generation. The two additional Pall filters were added to the system recently, when remaining charcoal was found in the solution. Thus, these filters have reduced the volume of waste alcohol solutions being generated due to charcoal contamination. ${ }^{4}$

Several organic dyes can be used in Diana, but the most frequently used dyes are Coumarin 440 and Coumarin 521. Coumarin 440 laser dye is used to generate laser light in the near UV spectrum $(430 \mathrm{~nm})$. Coumarin 521 is used to generate laser light in the visible light spectrum $(531 \mathrm{~nm}) .4,5$

While the Diana laser is running, the power supply sends power to the flashlamp, which causes it to pulse. The pulse from the flashlamp goes through the dye solution and excites the dye molecules. The dye molecules then release their energy in the form of light. These pulses are sent out to the various CRF laboratories through the laser beam distribution system. 4

Figure 2 shows the laboratory's general process flow.

Figure 2. Diana Laser General Process Flow Diagram.

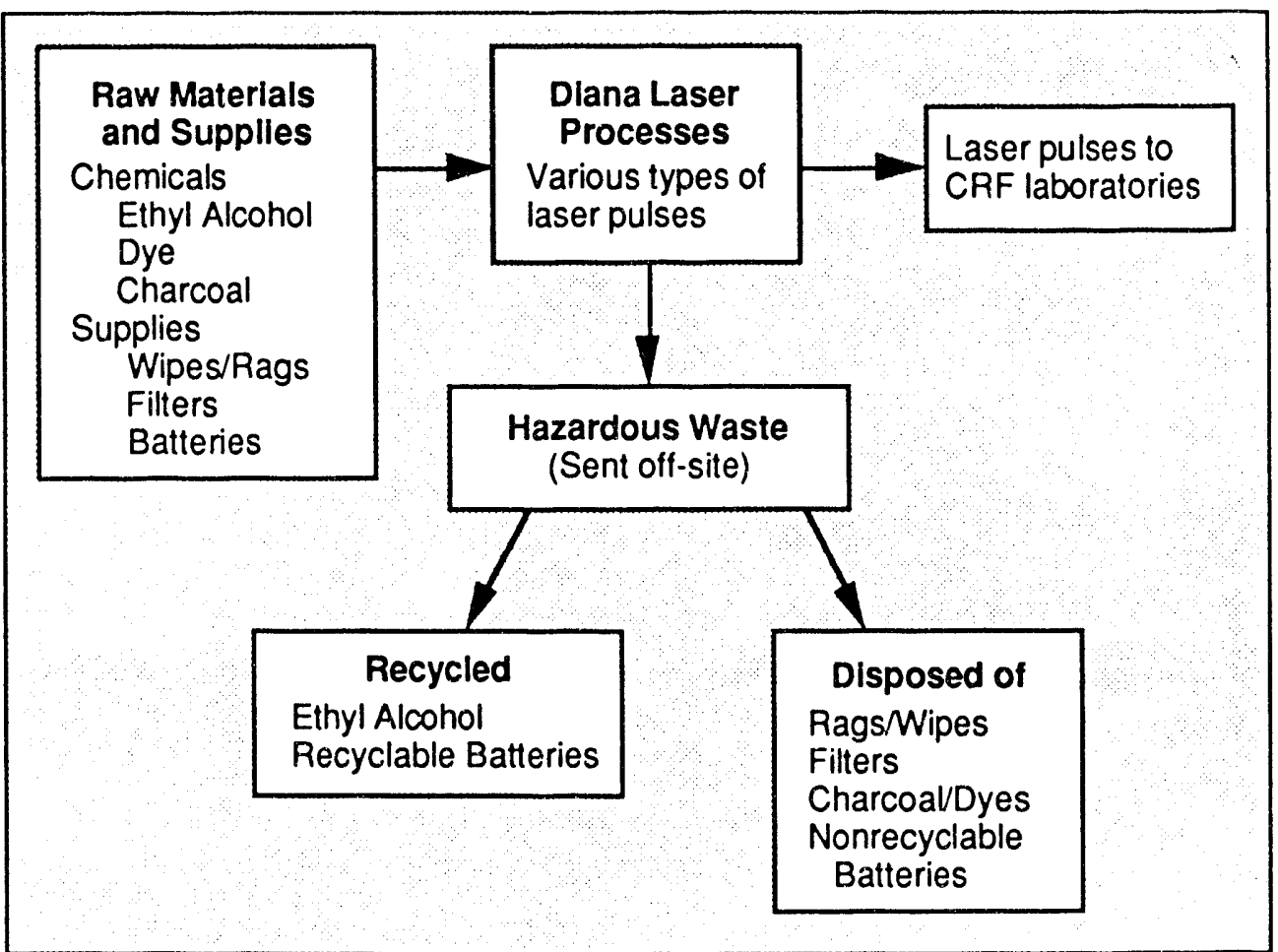




\section{Waste Generation}

Table 1 lists the various hazardous wastes generated by the laboratory from January 1992 to July 1993.7 The largest waste stream was the spent ethyl alcohol and dye solutions. These waste solutions are generated when the dye solution is changed from one type to another or when it has been spent by the laser pulses and can no longer be renewed by filtering and dye additions. The Coumarin 521 dye can be used for up to 80,000 laser pulses. The Coumarin 440 dye can be used for 4,000 to 5,000 pulses before requiring filtration. ${ }^{4}$ The solution can be filtered several times before it is spent. When spent, these solutions are sent off-site for recycling.

The second largest waste stream is charcoal filters contaminated with dye and residual alcohol. They are disposed of off-site as solid hazardous waste. This waste stream is generated when the dye solution is changed from one to another or when the charcoal becomes saturated. Spent Pall filters are also generated when the dye solutions are changed from one to another. These filters are disposed of as hazardous waste.

The volume of waste dye solutions and filters are expected to significantly decrease when planned operational changes for the Diana laser are implemented. The plan is to use Coumarin 440 dye exclusively. In this case, the dye solution may last up to two years. The charcoal and Pall filters will also last much longer under the new operation. ${ }^{4}$

Table 1. Diana Laser Hazardous Waste Generation (January 1992 to July 1993). ${ }^{7}$

\begin{tabular}{|c|c|c|c|}
\hline Waste Stream & Waste I.D. & $\begin{array}{l}\text { Volume } \\
\text { Generated }\end{array}$ & Cost of Disposal \\
\hline Alcohol & Ethyl Alcohol/Dye Solutions & 445 gal. & $\begin{array}{l}\$ 2.20 / \text { gal. } \\
\text { Total = } \$ 979\end{array}$ \\
\hline Rags & Rags and Wipes & $17 \mathrm{lbs}$. & $\begin{array}{l}\$ 950 / 55 \text {-gal. drum }+\$ 85 \\
\text { transportation } \\
\text { Total }=\$ 72\end{array}$ \\
\hline Batteries & $\begin{array}{l}\text { Alkaline } \\
\text { Lithium } \\
\text { Mercury }\end{array}$ & $\begin{array}{r}105 \mathrm{ea} . \\
2 \mathrm{ea} . \\
19 \mathrm{ea} .\end{array}$ & $\begin{array}{l}\$ 0.40 / \mathrm{lb} .+\$ 8.12 / \mathrm{lb} . \\
\text { transportation } \\
\text { Total }=\$ 378\end{array}$ \\
\hline $\begin{array}{c}\text { Empty } \\
\text { Containers }\end{array}$ & Empty Containers & $71 \mathrm{lbs}$. & $\begin{array}{l}\$ 950 / 55-\text { gal. drum }+\$ 85 \\
\text { transportation } \\
\text { Total = approx. } \$ 367\end{array}$ \\
\hline Filters & Filters & $51 \mathrm{lbs}$. & $\begin{array}{l}\$ 950 / 55-\text { gal. drum }+\$ 85 \\
\text { transportation } \\
\text { Total = approx. } \$ 216\end{array}$ \\
\hline Charcoal & Ethanol/charcoal/dye & 142 lbs. & $\begin{array}{l}\$ 950 / 55 \text { gal. drum }+\$ 85 \\
\text { transportation } \\
\text { Total = approx. } \$ 793\end{array}$ \\
\hline
\end{tabular}




\section{Process Flow and Material Balance}

Figure 3 shows the Diana laser process flow and an estimated material balance based on waste generation during 1992 . However, the material balance probably will change significantly in the future operations of the laboratory.

\section{Recommendations}

The following recommendations are suggested as potential waste minimization measures:

- Because a large volume of the hazardous waste generated by this process is a result of switching from one type of dye to another, the amount of waste generated can be greatly reduced by using only one type of laser dye. Based on information collected during this assessment, the plans for the facility's future operation already include this recommendation.

- As an alternative to the above recommendation, if the laser cannot run with only one type of dye solution, then an annual or semiannual schedule should be set up to minimize how often the type of dye is changed.

- The spent alcohol solution should still be sent off-site for recycling, rather than Sandia trying to reclaim it on-site. This process does not (and is not expected to) generate enough waste to make on-site reclamation practical or cost effective. Additionally, achieving the required solution purity level with a small recovery unit would be difficult.

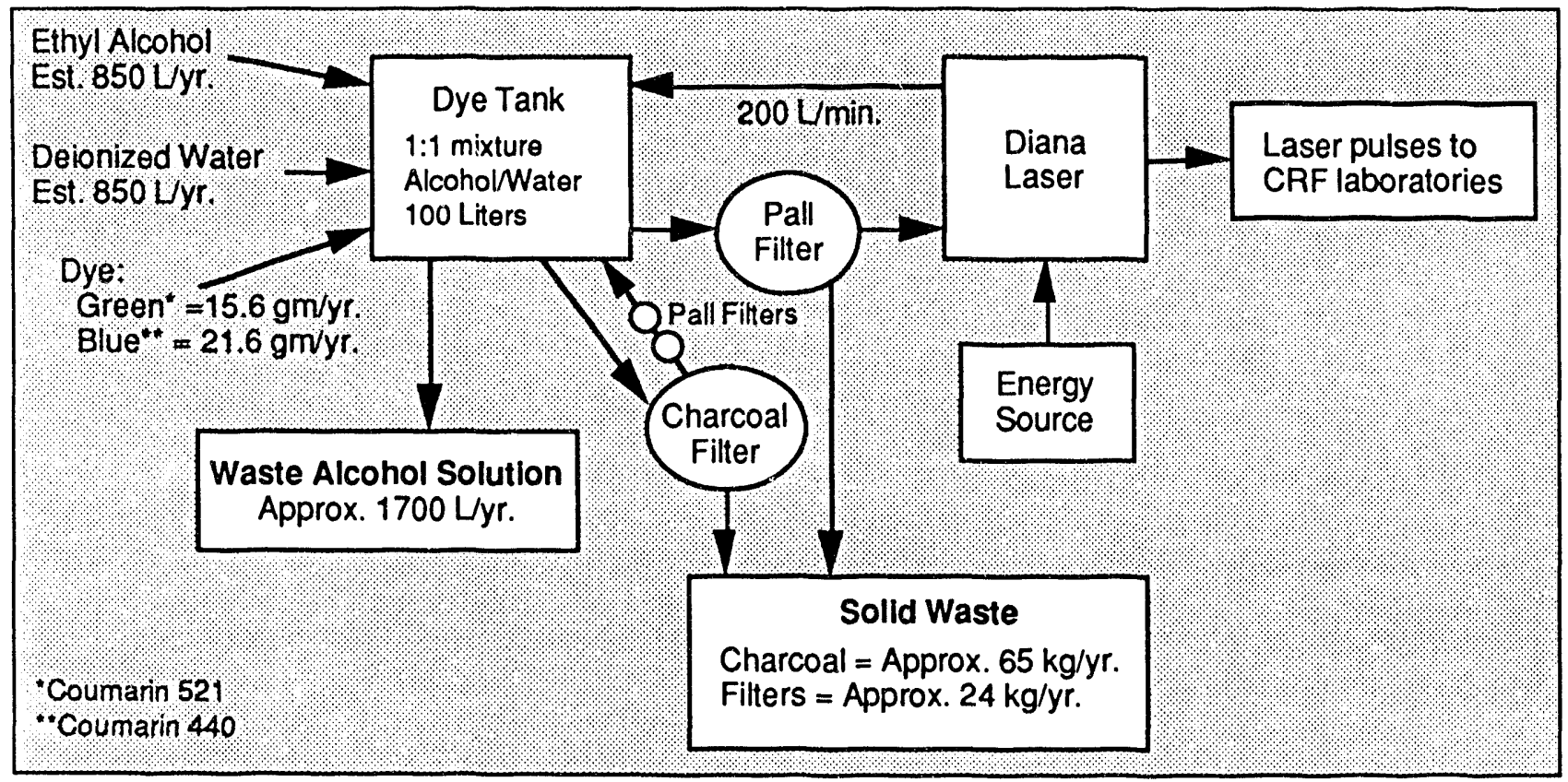

Figure 3. Diana Laser Process Flow and Estimated Material Balance. 


\section{References}

1. U.S. Department of Energy (DOE), Order 5400.1, General Environmental Protection Program (November 9, 1988).

2. U.S. DOE, Order 5400.3, Hazardous and Radioactive Mixed Waste Program (February 22, 1989).

3. U.S. DOE, SNL/California, Process Waste Assessment Plan (June 1993).

4. Wilkerson, George, 1993, Sandia Diana Laser Laboratory, personal communication with N. M. Phillips.

5. Volponi, Joanne, 1993, Sandia CRF Laboratory, personal communication with N. M. Phillips.

6. U.S. DOE, SNL/California, Standard Operating Procedures for Diana-Flashlamp-Pumped Dye Laser Laboratory, SOP- SP471938 (1991).

7. U.S. DOE, SNL/California, Environmental Protection Hazardous Waste Storage Log (1992 and 1993). 


\section{UNLIMITED RELEASE}

\section{INITIAL DISTRIBUTION}

U. S. Department of Energy (2)

Albuquerque Operations Office

Attn.: T. Pietrok, KAO

M. Williams, WMD

P. O. Box 5400

Albuquerque, NM 87115

MS1305, J. D. Fish, Org. 7576

MS1305, R. Davis, Org. 7576

MS9001, J. C. Crawford, Org. 8000

Attn.: D. L. Crawford, 1900

G. E. Ives, 5200

J. B. Wright, 5300

M. E. John, 8100

R. J. Detry, 8200

W. J. McLean, 8300

L. A. Hiles, 8400

P. E. Brewer, 8500

L. A. West, 8600

R. C. Wayne, 8700

MS9161, G. A. Wilkerson, Org. 8342

MS9055, J. V. Volponi, Org. 8353

MS9707, C. L. Knapp, Org. 8415

MS9021, K. W. Gordon, Org. 8535

MS9222, G. Faulkner, Org. 8642

MS9222, A. J. Johnson-Duarte, Org. 8642

MS9222, D. A. Nissen, Org. 8642

MS9222, N. M. Phillips, Org. 8642 (15)

MS9222, S. J. Raubfogel, Org. 8642

MS9222, K. K. Shepodd, Org. 8642

MS9021, Technical Communications for OSTI, Org. 8535 (10)

MS9021, Technical Communications/Technical Library Processes

MS0899, Technical Library Processes Department, Org. 7141 (4)

MS9018, Central Technical Files, Org. 8523-2 (3) 

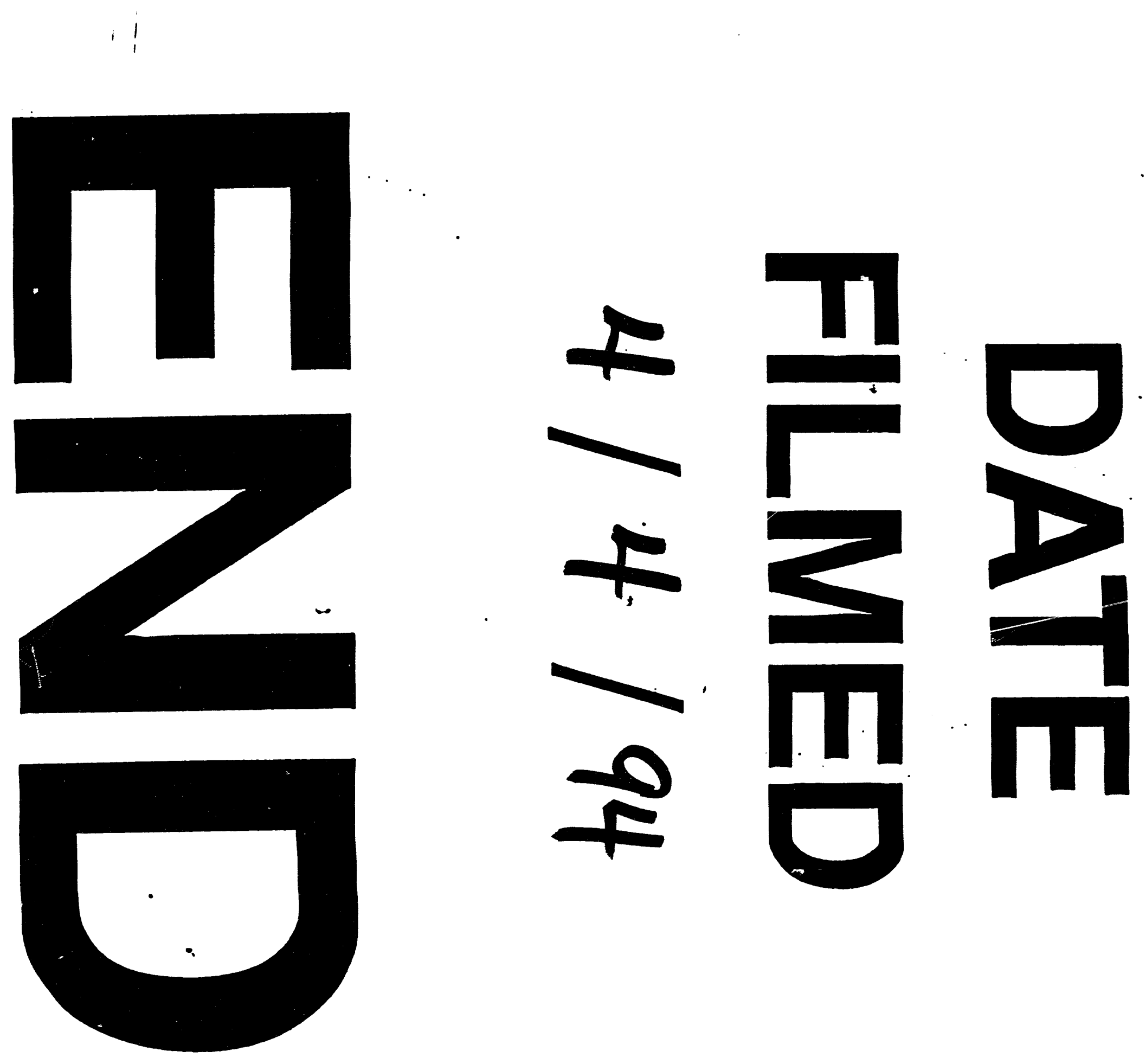